\title{
Evaluation of the immunogenicity and the protective efficacy in mice of a DNA vaccine encoding SP41 from Brucella melitensis
}

\author{
Ayman Al-Mariri and Abdul Q. Abbady \\ Department of Molecular Biology and Biotechnology, Atomic Energy Commission of Syria, \\ Damascus, Syria
}

\begin{abstract}
Introduction: Brucella melitensis is a facultative intracellular Gram-negative bacterial pathogen that may enter the host via ingestion or inhalation, or through conjunctiva or skin abrasions. Some Brucella spp surface proteins (SPs) play an important role in bacterial adhesion and invasion and thus represent targets for the host immune system. Brucella spp surface protein with apparent molecular mass of $41 \mathrm{kDa}$ interacts selectively with HeLa cells.

Methodology: To evaluate the role of SP41 (41 kDa) as a DNA vaccine against Brucella spp., pCISP41, a plasmid construct for protein expression in mammalian cells, was established. Exogenous SP41 was detected in pCISP41-transfected Vero cell line by immune blotting using specific polyclonal antibody. The protective role of pCISP41 against B. melitensis $16 \mathrm{M}$ in mice was evaluated by measuring B and T cell responses in comparison to those achieved with attenuated B. melitensis Rev. 1 vaccine.

Results: BALB/c mice injected with pCISP41 were able to develop SP41-specific serum immunoglobulin G (IgG) antibodies. In addition, splenocytes from DNA-SP41-vaccinated mice elicited a T-cell-proliferative response and also induced gamma interferon (IFN- $\gamma$ ) production, but not interleukin-5 (IL-5), suggesting the induction of a T-helper-1-dominated immune response. Vaccination with attenuated B. melitensis Rev.1 strain induced better protection levels than DNA vaccination with SP41 against B. melitensis 16M in mice.

Conclusion: Such responses play an important role against intracellular infecting agents such as Brucella spp. Altogether, our data suggest that SP41 may represent a promising candidate for DNA vaccination against brucellosis, but more investigation to increase its protective efficacy should be done.
\end{abstract}

Key words: Brucella; SP41; DNA vaccine; CMI; vaccine

J Infect Dev Ctries 2013; 7(4):329-337. doi:10.3855/jidc.2296

(Received 07 September 2011 - Accepted 10 May 2012)

Copyright (C) 2013 Al-Mariri et al. This is an open-access article distributed under the Creative Commons Attribution License, which permits unrestricted use, distribution, and reproduction in any medium, provided the original work is properly cited.

\section{Introduction}

Brucella melitensis is a facultative intracellular pathogen and one of the etiological agents of brucellosis that can infect humans and animals [1]. The disease brucellosis is a highly common bacterial zoonosis worldwide, and a major cause of human disease and economic loss of cattle [2]. Because of the economic losses to the sheep and goat industry caused by $B$. melitensis, as well as the zoonotic infections caused by these bacterial species, great efforts were made to eradicate ovine brucellosis worldwide [3]. To achieve this objective, a vaccine strain of $B$. melitensisRev.1 has been used with relatively good results [4]. However, Rev.1 has several drawbacks. For example, it is difficult to differentiate between vaccinated and naturally infected animals, as Rev.1 elicits antibodies against smooth lipopolysaccharide, and it induces abortion in pregnant animals showing a likelihood of changing to a virulent form and also be fully virulent for humans [5]. A vaccine that will be non-infectious to humans but effective in stimulating a broad protective immune response is needed to control brucellosis [6]. The host resistance to $B$. melitensis depends mainly on acquired cell-mediated immunity (CMI) [7]. In vivo, Th1 differentiation depends on IL12, and Th17 differentiation depends on IL-6 and TGF-b [7]. Th17 responses have been shown to contribute to host defense against several extracellular pathogens such as Klebsiella pneumoniae [2], as well as against intracellular microorganisms such as $B$. abortus [8]. The development of a Th1 subset of CD4+ lymphocytes secreting gamma interferon (IFN$\gamma)$ is important, since it is a crucial cytokine that can upregulate the anti-Brucella activity of macrophages $[9,10]$. The historical basis of DNA vaccines rests on the observation that direct in vitro and in vivo gene transfer of recombinant DNA by a variety of techniques resulted in the expression of protein [11]. 
DNA vaccination might provide several important advantages over current vaccines, as follows: (i) DNA vaccines mimic the effects of live attenuated vaccines in their ability to induce major histocompatibility complex (MHC) class I restricted CD8+ T-cell responses, which may be advantageous compared with conventional protein-based vaccines, while mitigating some of the safety concerns associated with live vaccines; (ii) DNA vaccines can be manufactured in a relatively cost-effective manner and stored with relative ease $[12,13]$; (iii) DNA vaccine provides prolonged antigen expression, leading to the amplification of immune response and induces memory responses against infectious agents [14]. This type of vaccine is capable of eliciting the strong CMI that is required for the control of infection by many intracellular agents [15]. This kind of immune response is of paramount importance against Brucellaspp [16]. Several studies of murine models have been conducted to test the abilities of different proteins of Brucella to induce a protective immune response. Recombinant antigens of Brucella spp. such as Bacterioferritine (BFR) and the P39 [17], HtrA [18], GroEL [19,20], GroES [21], Cu-Zn superoxide dismutase (SOD) [22,23], YajC [24], L7/L12 [25], outer membrane protein 31 (Omp31) [26], ialB and omp25 [16], BLS-L7/L12 [27], BLSOmp31 [28] and lumazine synthase [29] have been shown to induce humoral and CMI responses in mice. In addition, Omp31, P39, L7/L12, BLSOmp31, lumazine synthase and peptides comprising certain epitopes of $\mathrm{Cu}-\mathrm{Zn}$ SOD induced some level of protection in a mouse model of infection. Castañeda-Roldánet al. showed that a surface protein (SP41) of Brucella spp can bind to cellular sialic acid residues of HeLa cells [30]. SP41 is associated with bacterial adherence and invasion of HeLa cells. Adhesions in the form of outer membrane proteins may mediate direct binding of the bacteria to host cells or favor colonization by mediating bacteriabacteria interactions. Bacterial adherence is then considered an important virulence trait, because it enables bacterial pathogens to deliver toxins efficiently to host tissues, to interact closely with the cell membrane favoring intracellular penetration to overcome peristaltic clearance, and to establish microbial communities in biological niches [31]. Biochemical analysis of SP41 revealed that this protein is the predicted product of the ugpB locus, which showed significant homology to the glycerol-3phosphate-binding ATP-binding cassette (ABC) transporter protein that is found in several bacterial species. The aim of this study was to evaluate the protective capacity of immunization with plasmid DNA carrying the B. melitensis 16M SP41 gene (pCISP41).

\section{Methodology}

Animals

Seventy female BALB/c mice (7 to 8 weeks old, purchased from Charles River Laboratories, L'Arbresle, France) were randomly distributed into four experimental groups. The mice were kept in conventional animal facilities and received water and food.

\section{Bacterial strains and growth conditions}

$B$. melitensis $16 \mathrm{M}$ and vaccinated strain $B$. melitensis Rev.1 were obtained from the University of Namur (Belgium). Brucella was grown under optimal conditions in 2YT (peptone, $16 \mathrm{~g} / 1$; yeast extract, 10 $\mathrm{g} / 1 ; \mathrm{NaCl}, 5 \mathrm{~g} / 1$ and distilled water to 11 ) (Difco, USA) overnight at $37^{\circ} \mathrm{C}$ and $5 \% \mathrm{CO}_{2}$ to ensure sufficient cell density; or in 2YT-Agar (agar $13 \mathrm{~g} / \mathrm{l}$ ), for $72 \mathrm{~h}$ at $37^{\circ} \mathrm{C}$ and $5 \% \mathrm{CO}_{2}$ [17]. All experiments with live Brucella spp were performed in biosafety level 3 facilities. Escherichia coli strain TOP10 was used to prepare the plasmid constructs. The E. coli TOP10 cultures were routinely grown at $37^{\circ} \mathrm{C}$ in Luria-Bertani broth (LB) or agar and were supplemented, when required, with 100 $\mu \mathrm{g} / \mathrm{ml}$ ampicillin. For infection experiments, $B$. melitensis $16 \mathrm{M}$ were grown for 48 hours in $2 \mathrm{YT}$ agar. The bacteria were suspended in a sterile phosphatebuffered saline (PBS). B. melitensis $16 \mathrm{M}$ abundance in PBS was monitored by recording the optical density (OD) at $590 \mathrm{~nm}$. The exact doses were assessed retrospectively by viable counts on 2 YT agar plate.

\section{Production of recombinant SP41 protein}

Briefly, the respective gene SP41 was cloned into a $\mathrm{pET}-15 \mathrm{~b}$ expression vector and the resulting plasmid was introduced in E. coli BL21 (DE3) (Novagen, Madison, WI, USA); then the positive clones were selected. The recombinant proteins were expressed successfully in transformed bacteria by induction with isopropyl- $\beta$-D-thiogalactopyranoside (IPTG) in LB medium, and then purified with a Ni2-HiTrap chelating 5-ml prepacked column (Amersham Pharmacia Biotech, Freiburg, Germany) using imidazole as the elution reagent, according to the manufacturer's protocol. The lysates of transformed cells and the purified protein were identified by sodium dodecyl sulfate-polyacrylamide gel electrophoresis (SDS-PAGE) and Western blot assays. The purified protein was then stored at $-70^{\circ} \mathrm{C}$ until 
used for enzyme-linked immunosorbent assay (ELISA) or for in vitro stimulation of splenocytes.

\section{Polyclonal antibodies against SP41}

A New Zealand white female rabbit was injected intradermally with $100 \mu \mathrm{g}$ of rSP41 in Freund's adjuvant (complete for the initial injection; incomplete for subsequent intramuscular injections) diluted 1:1 with sterile saline. Three inoculations were performed at two-week intervals. Antisera were then collected 10 days after the last injection. Working dilutions of 1:500 of antisera were used in this work.

\section{Subcloning of SP41 gene in mammalian expression plasmid $p C I$}

Oligonucleotide primers were designed to amplify the whole sequence of SP41 gene from B. melitensis bv. 1 str. $16 \mathrm{M}$ based on the published corresponding genomic sequences (GeneBank accession no. NC_003318). SP41 gene is located in the B. melitensis bv. 1 str. $16 \mathrm{M}$ chromosome II in a complementary position from $659855 \mathrm{bp}$ to $661156 \mathrm{bp}$. A large gene fragment containing a full-length open reading frame of SP41 gene was first amplified by PCR from the genomic DNA of $B$. melitensis $16 \mathrm{M}$ using (forward) 5'TAAAGATCCAGAGGAGCTTT-3' and (reverse) 5'CATTGTCTCGATATGATGGA-3'. The first PCR product was used as a template in a second PCR run to amplify the exact SP41 gene length by its original start and stop codons. For this aim, primers were designed according to the SP41 gene nucleotide sequence and contained one artificial restriction site at each end: (forward)

ATACACTCGAGATGTTCACCCGTCTGATCACG

$-3^{\prime}$ and (reverse) 5'-

CGAGATCTAGAATTATTGAGCTGCGGCGATTG

-3 ', where the underlined nucleotides indicate the position of XhoI and XbaI restriction enzymes (Fermentas GMBH, Opelstraße, Germany), respectively. The amplified SP41 gene fragment was subcloned into the mammalian expression vector $\mathrm{pCI}$ downstream of the cytomegalovirus promoter (Promega, Boston, USA). PCR was performed in a 10 $\mu \mathrm{l}$ volume containing $1 \mathrm{ng}$ DNA template, 5 pmol of each primer, $10 \mathrm{mM}$ deoxyribonucleoside triphosphate, 10× PCR buffer, and $5 \mathrm{U}$ AmpliTaq polymerase (Qiagen, Valencia, USA). PCR amplification was conducted with a DNA thermal cycler under the following conditions: denaturation at $95^{\circ} \mathrm{C}$ for 3 minutes, annealing at $55^{\circ} \mathrm{C}$ for 45 seconds and extension at $72^{\circ} \mathrm{C}$ for one minute ( 35 cycles). The amplified products were purified with the Quiaex II gel extraction kit (Qiagen) and digested with XhoI and $\mathrm{XbaI}$ restriction endonucleases. After digestion, the PCR product was purified again by the same procedure and ligated to the predigested pCI vector. This construction was used to transform E. coli TOP10, and a single recombinant clone was selected. Plasmid DNA was extracted with the Miniprep kit (Qiagen). The pCISP41 construct was digested with endonucleases and DNA sequenced to confirm the presence and the orientation of the SP41 gene. For large-scale plasmid DNA isolation, a colony of E. coli TOP10 containing pCISP41 was cultured in LB containing $100 \mu \mathrm{g} / \mathrm{ml}$ ampicillin and DNA isolation was performed using an EndoFree Plasmid Giga kit (Qiagen) according to the manufacturer's directions. The DNA was finally resuspended in PBS at a concentration of $1 \mathrm{mg} / \mathrm{ml}$. The DNA concentration and purity were determined by the $\mathrm{OD}$, and the A260/A280 ratio was typically $>1.8$.

\section{Antigen expression in Vero cell line}

Monkey kidney Vero cells were grown at $37^{\circ} \mathrm{C}$ in $5 \% \mathrm{CO} 2$ in six-well plates (TTP, Trasadingen, Swaziland) containing Dulbecco's modified Eagle's medium (DMEM) (Gibco, BRL, Essen, Germany) supplemented with $10 \%$ fetal bovine serum (FBS), 2 $\mathrm{mM}$ L-glutamine, penicillin $(100 \mathrm{U} / \mathrm{ml})$, and gentamicin $(50 \mu \mathrm{g} / \mathrm{ml})$, and subconfluence monolayers were washed once with serum-free DMEM. Afterwards, $500 \mu$ of DMEM (supplemented as above, but without FBS) was added. Then $100 \mu \mathrm{l}$ of transfection mixture $(100 \mu \mathrm{l}$ of serum-free DMEM containing $6 \mu \mathrm{g}$ of Fugene 6 Boehringer, Ingelheim, Germany) and $1 \mu \mathrm{g}$ of plasmid DNA were kept at room temperature (RT) for 5 minutes and added to the cells, which were then incubated at $37^{\circ} \mathrm{C}$ in $5 \% \mathrm{CO}_{2}$ overnight [17]. Expression of SP41 protein was detected by immunoblotting.

\section{SDS-PAGE and Western blot analysis}

SDS-PAGE was performed using standard procedures for Western blot analysis, and proteins were transferred from the gel $(12 \% \mathrm{wt} / \mathrm{vol}$ polyacrylamide) to $0.2 \mu \mathrm{m}$-pore-size nitrocellulose membranes (Bio-Rad, Hercules, USA).The assay was achieved using the rabbit anti-SP41 polyclonal antibody and the purified recombinant SP41 protein (rSP41) as a control. Membranes were probed with an anti-SP41 and then with a goat anti-rabbit IgG conjugated to horseradish peroxidase (Bethyl Laboratories, Inc., Montgomery, USA). Detection of SP41 antigen was achieved upon development with 
the TMB membrane substrate (3,3,5,5-tetramethyl benzidine) (Amresco, Solon, OH, USA) in citratephosphate buffer $(0.05 \mathrm{M} \mathrm{Na} 2 \mathrm{HPO} 4,0.025 \mathrm{M}$ citric acid, $\mathrm{pH}$ 5.0) and $2 \mathrm{mM} \mathrm{H}_{2} \mathrm{O}_{2}$ were added to monitor the peroxidase activity.

\section{Mice DNA vaccination and challenge}

Mice randomly allocated in three groups of 20 mice each received intramuscular (i.m.) injections in the tibialis anterior muscles as follows: one group received $100 \mu \mathrm{g}$ of $\mathrm{pCISP} 41$, one group received $\mathrm{pCI}$ as a negative control in $50 \mu 1$ sterile saline (PBS), and one group was treated with $50 \mu 1$ of saline by using a $1-\mathrm{ml}$ insulin syringe with a 28 -gauge needle. Three vaccinations at three-week intervals were performed. The immune response (five mice per group) was analyzed four and eight weeks after the last DNA vaccination. Positive control mice $(n=10)$ received an intraperitoneal (i.p.) injection with 1 x $105 \mathrm{CFU}$ of Rev.1 in $100 \mu$ of sterile PBS four weeks before the challenge. Thirty days after the last DNA injection, 10 mice per group were challenged i.p. with approximately $3 \times 10^{5} \mathrm{CFU}$ of $B$. melitensis $16 \mathrm{M}$ in $100 \mu \mathrm{l}$ of sterile PBS, and ten mice per group were sacrificed to conduct an analysis of immune responses, including $\mathrm{IgG}$, proliferation cells, and cytokine production.

\section{Quantification of bacteria in the spleen}

Protection experiments were performed as previously described [32]. Briefly, at four and eight weeks post-challenge, five mice were killed by cervical dislocation, and their spleens were removed, homogenized, and dilutions were plated to determine the number of Brucella spp CFU per spleen. Three repeats were performed for each mouse, and then the mean of these repeats was calculated and considered as the average CFU number of each mouse. Log 10 units of protection were obtained by subtracting the mean $\log _{10} \mathrm{CFU}$ for the experimental group from the mean $\log _{10} \mathrm{CFU}$ of the corresponding control group.

\section{ELISA}

The presence of serum IgG specific to rSP41 was determined by indirect ELISA on the 30th day after the final immunization. Purified rSP41 was diluted to $0.01 \mathrm{mg} / \mathrm{ml}$ in carbonate buffer $(\mathrm{pH}$ 9.6) and used to coat the wells of a polystyrene plate $(100 \mu \mathrm{l} /$ well; (MaxiSorp surface; Nunc, Waltham, USA) or with $B$. melitensis $16 \mathrm{M}$ bacterial lysate at a concentration of 3 $\mu \mathrm{g} / \mathrm{ml}$. After overnight incubation at $4^{\circ} \mathrm{C}$, the plates were washed, blocked, and incubated with serially diluted sera for three hours at RT. Following another washing, IgG goat anti-mouse horseradish peroxidase conjugates were added $(100 \mu \mathrm{l} /$ well $)$ at the appropriate dilutions. After one hour of incubation at RT, the plates were washed, and TMB in citrate-phosphate buffer ( $\mathrm{pH}$ 5.0) and $2 \mathrm{mM} \mathrm{H}_{2} \mathrm{O}_{2}$ were added to each well to monitor peroxidase activity. The enzymatic reaction was allowed to proceed for 20 minutes at room temperature; then the reaction was stopped with the addition of $50 \mu 1$ of $1 \mathrm{M}$ sulfuric acid per well. The absorbance of the developed color was measured at $450 \mathrm{~nm}$ in a Multiskan, Thermo-lab Systems Reader, Vantaa, Finland. The titer of each serum was calculated as the $\log 10$ of the reciprocal of the highest serum dilution yielding a specific OD higher than the cutoff value. All assays were performed in triplicate for each mouse, and their mean was considered as the average of each mouse.

\section{Splenocyte culture and lymphocyte proliferation}

Four to eight weeks after the last immunization, mice were sacrificed, and their spleens removed under aseptic conditions. Single-cell suspensions were prepared from the spleens, and red blood cells were lysed with ACK $\left(150 \mathrm{mM} \mathrm{NH}{ }_{4} \mathrm{Cl}, 1 \mathrm{mM} \mathrm{KHCO}{ }_{3}, 0.1\right.$ $\mathrm{mM}$ Na2EDTA, $\mathrm{pH}$ 7.3). Splenocytes were cultured at $37^{\circ} \mathrm{C}$ in $5 \% \mathrm{CO}_{2}$ in a 96 -well flat-bottom plate at a concentration of $2 \times 105$ cells per well in RPMI 1640 medium supplemented with $2 \mathrm{mM}$ L-glutamine and $10 \%$ heat-inactivated FBS (Eurobio, Courtaboeuf, France), in the presence of concanavalin A (ConA; 3 $\mu \mathrm{g} / \mathrm{ml}), \mathrm{rSP} 41(1 \mu \mathrm{g} / \mathrm{ml})$, bacteria lysate $(4 \mu \mathrm{g} / \mathrm{ml})$, or no additive in culture medium for a total volume of 0.1 $\mathrm{ml}$ per well. Cell proliferation was determined in triplicate using a ALEXIS Biochemicals Cell Counting Kit-F (Lausen, Switzerland). After incubation for 72 hours at $37^{\circ} \mathrm{C}$ in $5 \% \mathrm{CO}_{2}$, the plates were washed three times with D-PBS(-) to remove esterase and phenol red, then $100 \mu 1$ of D-PBS(-) was left in each well. Next $10 \mu \mathrm{l}$ of CCK-F working solution was added to each well and plates were incubated at $37^{\circ} \mathrm{C}$ for 30 minutes [32]. Measurement of the fluorescence intensity of each well was performed at $535 \mathrm{~nm}$ (excitation at $485 \mathrm{~nm}$ ) using a fluorescence plate reader (FluoroSkan Ascent FL, Thermo-Electron Corporation, Helsinki, Finland). The mean number of cells count and the standard error of the mean for each mouse group were also determined.

In vitro assay for cytokine production by spleen cells

Levels of IFN- $\gamma$ and interleukin-5 (IL-5) in murine splenocyte culture supernatants were measured after 
Table. Protection of BALB/c mice against challenge with $B$. melitensis $16 \mathrm{M}$ after immunization with pCISP41 or attenuated B. melitensis strain Rev. $1^{\mathrm{a}}$

\begin{tabular}{|c|c|c|c|c|c|}
\hline \multirow{2}{*}{$\begin{array}{l}\text { mice group } \\
(\mathrm{n}=5)\end{array}$} & \multirow{2}{*}{ Vaccine } & \multicolumn{2}{|c|}{$\begin{array}{l}\log _{10} \text { CFU of } B . \text { melitensis } 16 \mathrm{M} \\
\text { in spleen }(\text { mean }+\mathrm{SD})\end{array}$} & \multicolumn{2}{|c|}{$\log _{10}$ units ofprotection } \\
\hline & & $4 w$ & $8 w$ & $4 w$ & $8 w$ \\
\hline 2 & $\mathrm{pCI}$ & $5.71 \pm 0.29$ & $5.36 \pm 0.11$ & - & - \\
\hline 3 & pCIsp41 & $4.42 \pm 0.35$ & $4.12 \pm 0.17$ & $1.25^{\mathrm{b}}$ & $1.14^{\mathrm{c}}$ \\
\hline
\end{tabular}

96 hours of incubation with antigen or mitogen as described for the lymphocyte proliferation assay. IFN$\gamma$ and IL-5 were assayed by specific ELISA kits (EuroClone, CITY, Italy), and samples were tested in duplicate. The concentration of IFN- $\gamma$ or IL-5 in the culture supernatants was calculated via a linearregression equation obtained from the absorbance values of the standards as indicated by the manufacturer. Values of less than 40 and $10 \mathrm{pg} / \mathrm{ml}$ were considered negative for IFN- $\gamma$ and IL-5, respectively.

\section{Statistical methods}

Statistical analyses were performed with student's t-test. Log units of protection were obtained by subtracting the mean counts of the vaccinated group from the mean of the corresponding control group. A mean value for each spleen count was obtained by averaging the triplicate values after log conversion.

\section{Results}

Construction and testing of the plasmid construct pCISP41

To study the roles of SP41 as a potential DNA vaccine in immune response and protective immunity induced against brucellosis, we prepared a plasmid construct able to express SP41 in mammalian cells, pCISP41. The recombinant plasmid was verified by restriction digestions and sequencing. To verify the ability of the constructed DNA vaccine to be correctly expressed in mammalian cells, we transformed Vero cells with pCISP41 and the expression of exogenous SP41 was shown by Western blot assay using a homemade SP41-specific polyclonal antibody (Figure 1). As expected, a $41-\mathrm{kDa}$ protein, similar to the detected rSP41, was found in the lysate of pCI-SP41 transformed Vero cells and not in the control cells transformed with empty plasmid pCI (Figure 1).
Immune response of $B A L B / c$ mice vaccinated with pCISP 41

To evaluate the induction of humoral immunity using pCISP41 as DNA vaccination in mice, the titers of anti-SP41 antibodies in mouse sera were measured by ELISA, using total $B$. melitensis lysate or rSP41 as immobilized antigens. As expected, IgGresponse in mice immunized with pCISP41 against both types of antigens were seen four weeks after vaccination (reciprocal dilutions of sera were 1500 and 2000, respectively). On the contrary, specific anti-SP41 antibodies were not detected in sera of mice inoculated with pCI or PBS (Figure 2). Significant differences were observed in the amount of $\mathrm{IgG}$ produced by DNA vaccine and by the pCI vector control $(P<0.01)$.

To examine the CMI response to rSP41 protein and crude $B$. melitensis proteins, the proliferation response and cytokine profile of spleen cells from mice immunized with pCISP41, pCI, and PBS were determined. As shown in Figure 3A, significant T-cell proliferation response to $\mathrm{rSP} 41$ protein and lysed bacteria was seen four weeks after immunization $(P<$ 0.05) compared with the PBS group in the lymphocytes of mice immunized with pCISP41, whereas, Figure 3B shows a significant splenocytes proliferation response to specific antigens eight weeks after mice immunization with pCISP41 in vitro. With respect to cytokine profile, supernatants of spleen cell cultures from pCISP41-immunized animals contained high levels of IFN- $\gamma(P<0.05)$ compared to the negative control groups; however, IL-5 has not been produced in all culture supernatants of splenocytes stimulated with specific antigens (data not shown). Splenocytes stimulated with concanavalin A have produced the same high levels of IFN- $\gamma$ in all mice groups, including the control group (Figure 4). 
Figure 1. Expression of recombinant plasmid pCISP41 in Vero cells

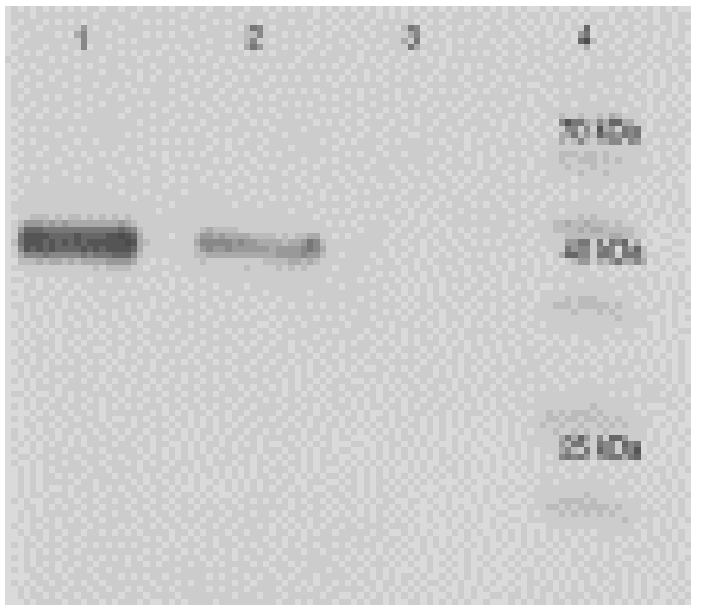

The lysates of Vero cells transformed with the recombinant plasmids were analyzed for the respective target protein expression by Western blot assay. Vero cells were transformed with pCISP41 (lane 2) or pCI (lane 3) as negative control. Loaded sample containing rSP41 $(0.5 \mu \mathrm{g})$ was used as positive control (lane 1). Lane (4), molecular size protein markers. A molecular mass of the target protein is indicated beside the figure.

Figure 3. Lymphocytes proliferation assay

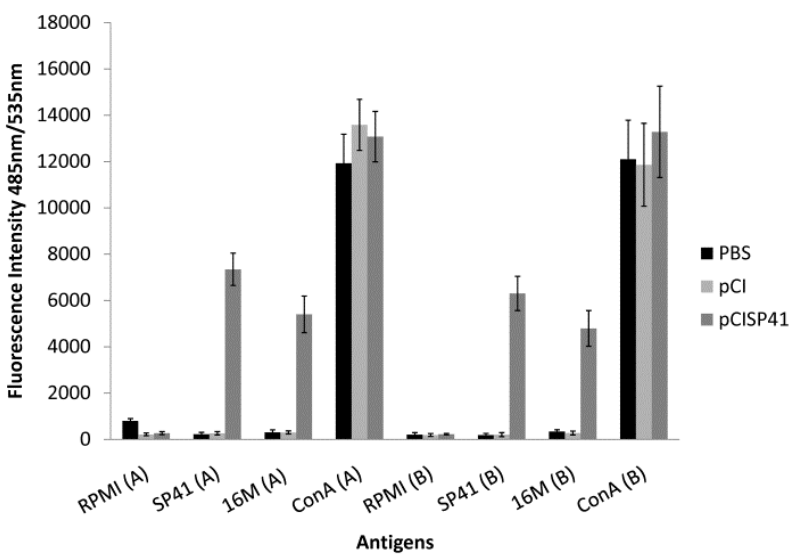

$\mathrm{BALB} / \mathrm{c}$ mice were immunized with PBS, parental plasmid $\mathrm{pCI}$ or pCISP41. At week 4 (to the left - A) or 8 (to the right - B) after immunization, splenocytes at $2 \times 10^{5}$ per well from each mouse were prepared and stimulated in vitro with rSP41 (1 $\mu \mathrm{g} / \mathrm{ml})$, bacterial lysate of B. melitensis $16 \mathrm{M}(4 \mu \mathrm{g} / \mathrm{ml})$, ConA (3 $\mu \mathrm{g} / \mathrm{ml})$ as positive control or without antigen as negative control (RPMI). Cell proliferation was determined using Cell Counting kit-F. Data represent the mean \pm standard deviation (error bars) from the five mice.
Figure 2. Antibody profile of mice immunized with various DNA vaccines

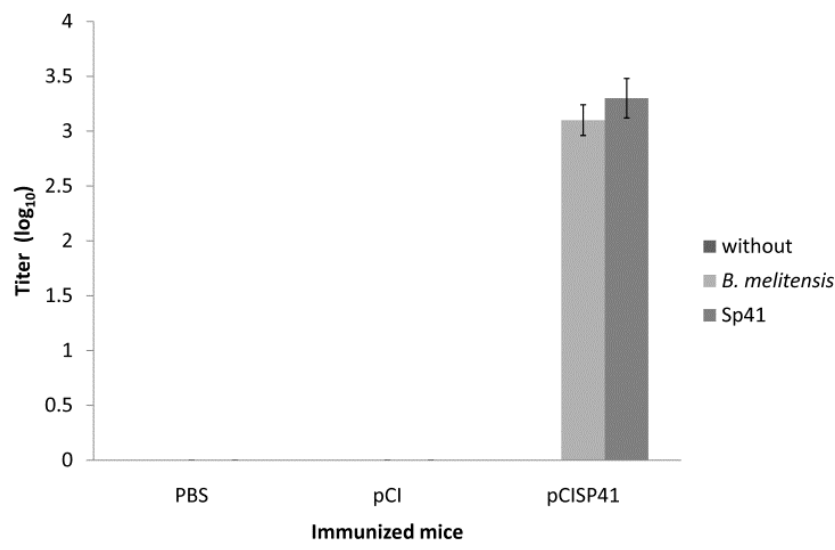

Mice (five per group) were injected either by pCISP41 (as a vaccine), or by pCI or PBS as negative controls. Four weeks after the last immunization, sera were collected from the experimental mice, and antibody titers were evaluated by ELISA in the absence (without) or the presence of immobilized rSP41 or Brucella lysate as antigens. The IgG amount was higher in pCISP41 group compared with pCIimmunized group, $P<0.01$. Data represent the mean \pm standard deviation (error bars) from the five mice.

Figure 4. In vitro splenocytes secretion of IFN- $\gamma$ upon stimulation with different antigens

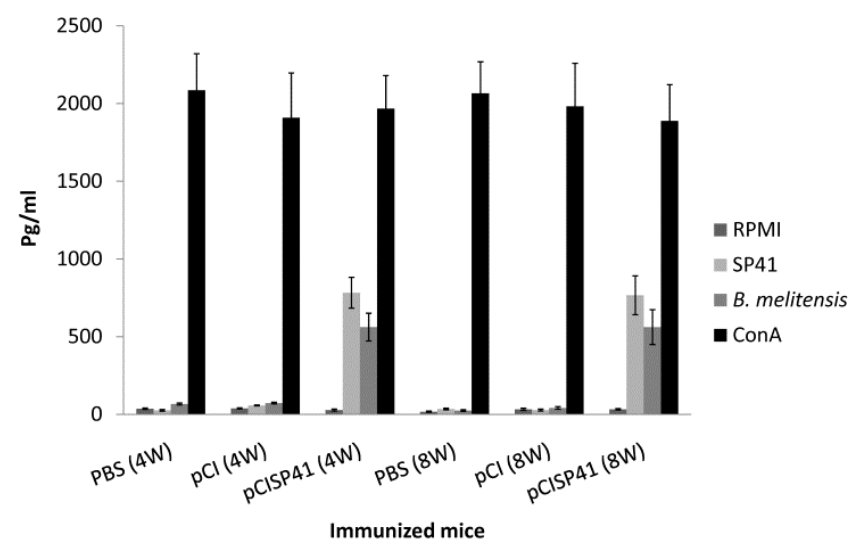

$\mathrm{BALB} / \mathrm{c}$ mice were inoculated i.m. with pCISP41, pCI or with PBS and killed 4 weeks after the last injection. $2 \times 10^{5}$ CFU of splenocytes were isolated and cultured in 96-well plates in triplicate without antigen (RPMI) as negative control, or with stimulation with $\operatorname{rSP} 41(1 \mu \mathrm{g} / \mathrm{ml})$, or bacterial lysate of $B$. melitensis $16 \mathrm{M}(4 \mu \mathrm{g} / \mathrm{ml})$, or ConA $(3 \mu \mathrm{g} / \mathrm{ml})$ as positive control of the assay. After $96 \mathrm{~h}$, supernatants were collected and tested for IFN- $\gamma$ production by sandwich ELISA. *Statistically significant differences compared to RPMI1640 $(P<0.05)$. Data represent the mean \pm standard deviation (error bars) from the five mice. 


\section{Protective efficacy}

Immunization with pCISP41 resulted in a significantly higher degree of protective efficacy, compared with that done by pCI or PBS, four and eight weeks post-injection $(P<0.05$ and $P<0.005$, respectively). However, vaccination with Rev.1 induced a higher level of protection, four and eight weeks post-infection, compared to mice injected with pCISP41 [1.79 and $3.17 \mathrm{log}$, respectively $(P<0.05)]$. No significant differences in CFU counts were seen among mice injected with pCI or PBS (Table).

\section{Discussion}

Conventional attenuated or inactivated vaccines have the disadvantage that they can produce adverse side-effects. The improvement to the methods of cloning and purifying proteins has led to the use of purified recombinant proteins as cellular vaccines in experimental trials. These preparations as well as the synthetic peptides are more convenient to use than attenuated vaccines but are not able to confer a high degree of protection or induce a strong CMI response [23]. In view of this situation, recent vaccine research has concentrated on the development of alternative vaccines, such as DNA vaccines. These involve the inoculation with an expression vector that encodes an antigenic protein; the encoded antigen is then produced in situ and elicits an immune response [33]. Vaccination with plasmid DNA has several advantages compared to the traditional formulations that are applicable to the development of vaccines for biodefense [34]. DNA vaccines, also known as dgeneticT, dnucleicacidT or dpolynucleotideT vaccines, deliver genes encoding protein antigens into host cells, enabling antigen production to occur in vivo [35]. Consequently, both strong cellular and humoral immune responses may be induced. In addition, the ability to genetically manipulate DNA offers the advantage of vaccines designed to produce costimulatory molecules, or the ability to target protein production to specific cell compartments to modulate the specificity of the immune response [35]. However, the most serious disadvantages of DNA vaccination are the possibility to induce either: (i) the transformation due to integration of DNA into the host cell genome, or (ii) the development of autoimmunity due to induction of T cells to cryptic epitopes [33].

The i.m. injection is the most common route of DNA administration. It seems that dendritic cells, professional antigen-presenting cells, play a major role in the initiation of an immune response in DNA vaccination by efficiently priming $\mathrm{T}$ cells with exogenous or endogenous antigens [14].

In DNA vaccination against brucellosis, injection of vector encoding either P39 [17] or SOD [36] by this route elicits protection against pathogen infection. In this study, we showed that i.m. injection of a DNA vector containing the DNA insert of $B$. melitensis SP41 was able to generate a moderate protective immune response. It is well documented that CMI plays a major role in the establishment of a protective response against Brucella spp [3], and for that reason the design of a preventive vaccine against brucellosis must be based on its capacity to generate a strong Th1type immune response, with high levels of IFN- $\gamma$ and T-cytotoxic activity involved in the immune process [37]. Our results show that the mice immunized with the DNA-SP41 vaccine exhibited remarkable titers of total IgG; and the mean antibody endpoint titers against rSP41 and lysed $B$. melitensis were respectively 9- and 7- folds higher than those induced by the pCI vaccine (Figure 2). These titers were similar to those previously found in several described Brucellaspp DNA vaccines [17,29]. T-cell immune response induction after DNA immunization was evaluated by measuring lymphocyte proliferation and cytokine production after in vitro stimulation of splenic cells with purified rSP41 or crude $B$. melitensisextract. Both conditions induced a higher Tcell level against B. melitensis proliferative response (Figure 3) and high levels of secreted IFN- $\gamma$ (Figure 4). By contrast, no detectable levels of IL-5 were present in the supernatants (data not shown). Our present results suggest that immunization with a SP41based DNA vaccine was able to induce a strong Th1type response that could be detected in T-cell cultures from vaccinated $\mathrm{BALB} / \mathrm{c}$ mice. However, theoretically, we suppose that our vaccine was not able to elicit a strong CMI response, which is necessary to provide a sufficient protection against $B$. melitensis 16M infection, compared to a live Brucella vaccine (Rev.1). This finding concurs with those of other studies, which reported that a DNA vaccine encoding L7-L12 [38], SOD [36] or P39 [17] induced an appropriate immune response, and conferred a moderate protection in $\mathrm{BALB} / \mathrm{c}$ mice challenged with Brucella spp compared to that observed in positive control mice vaccinated with live vaccine S19. In contrast, Cassataro et al. found that the vaccination of BALB/c mice with DNA vaccine coding for the chimera BLSOmp31 (pCIBLSOmp31) provided similar protection as Rev.1 against B. melitensis [28]. 
In spite of the relative failure of the pCISP41 as a competitor vaccine, we remain confident of the potentials of SP41, because of its important role in Brucellaspp adhesion and invasion.

Castañeda-Roldánet al. suggested that SP41 protein is produced in vivo and that it elicits an antibody immune response [30]. The antibodies directed against the SP41 inhibited bacterial adherence and invasion of HeLa or epithelial cells [30,31]. Luo et al. found that divalent DNA vaccine encoding both the L7/L12 and Omp16 genes elicit protective immunity against B. abortus in BALB/c mice [39]. Moreover, $\mathrm{Yu}$ et al. showed that combined DNA vaccine encoding BCSP31, SOD, and L7/L12 confers high protection against B. abortus 2308 [40]. Such interesting propositions are compelling to test our vaccine candidate SP41 in different vaccine formulations (e.g., adding $\mathrm{CpG} \mathrm{ODN}$ as adjuvant or using a live delivery vector) or in combination with several already-used DNA-encoded vaccines (e.g., P39, L7/L12 or/and SOD). These studies are currently under investigation in our laboratory.

\section{Acknowledgements}

The authors would like to thank the Director General of AECS, and the head of the Department of Molecular Biology and Biotechnology for their support.

\section{References}

1. Meng XJ, Lindsay DS, Sriranganathan N (2009) Wild boars as sources for infectious diseases in livestock and humans. Philos Trans R Soc Lond B Biol Sci 27: 2697-2707.

2. Ye P, Garvey PB, Zhang P, Nelson S, Bagby G, Summer WR, Schwarzenberger P, Shellito JE, Kolls JK (2001) Interleukin17 and lung host defense against Klebsiella pneumoniae infection. Am J Respir Cell Mol Biol 25: 335-340.

3. Glynn MK and Lynn TV (2008) Brucellosis. J Am Vet Med Assoc 15: 900-908.

4. Blasco JM (2010) Control and eradication strategies for Brucella melitensis infection in sheep and goats. Prilozi 31: 145-165.

5. Blasco JM (1997) A review of the use of B. melitensis Rev 1 vaccine in adult sheep and goats. Prev Vet Med 31: 275-83.

6. Neubauer H (2010) Brucellosis: new demands in a changing world. Prilozi 31: 209-217.

7. Baldwin CL, Goenka R (2006) Host immune responses to the intracellular bacteria Brucella: does the bacteria instruct the host to facilitate chronic infection? Crit Rev Immunol 26: 407-442.

8. Pasquevich KA, Ibañez AE, Coria LM, García Samartino C, Estein SM,Zwerdling A, Barrionuevo P, Oliveira FS, Seither C, Warzecha H, Oliveira SC, Giambartolomei GH, Cassataro J. (2011) An oral vaccine based on U-Omp19 induces protection against $B$. abortus mucosal challenge by inducing an adaptive IL-17 immune response in mice. PLoS One 146: e16203.
9. de Bagüés Jiménez MP, Ouahrani-Bettache S, Quintana JF, Mitjana O, Hanna N, Bessoles S, Sanchez F, Scholz HC, Lafont V, Köhler S, Occhialini A (2010) The new species Brucellamicroti replicates in macrophages and causes death in murine models of infection. J Infect Dis 202: 3-10.

10. Zhan Y and Cheers C (1993) Endogenous gamma interferon mediates resistance to Brucella abortus infection. Infect Immun 61: 4899-4901.

11. Stevenson FK (2004) DNA vaccines and adjuvants. Immunological Reviews 199: 5-8.

12. Kurath G, Garver KA, Corbeil S, Elliott DG, Anderson ED, LaPatra SE (2006) Protective immunity and lack of histopathological damage two years after DNA vaccination against infectious hematopoietic necrosis virus in trout. Vaccine 24: 345-54.

13. Liu F, Shollenberger LM, Conwell CC, Yuan X, Huang L (2007) Mechanism of naked DNA clearance after intravenous injection. J Gene Med 9: 613-619.

14. Ingolotti $\mathrm{M}$, Kawalekar $\mathrm{O}$, Shedlock DJ, Muthumani K, Weiner DB (2010) DNA vaccines for targeting bacterial infections. Expert Rev Vaccines 9: 747-763.

15. Peng S, Monie A, Kang TH, Hung CF, Roden R, Wu TC (2010) Efficient delivery of DNA vaccines using human papillomavirus pseudovirions. Gene Ther 17: 1453-1464.

16. Commander NJ, Brewer JM, Wren BW, Spencer SA, Macmillan AP, Stack JA (2010) Liposomal delivery of p-ialB and p-omp25 DNA vaccines improves immunogenicity but fails to provide full protection against $B$. melitensis challenge. Genet Vaccines Ther 16: 5.

17. Al-Mariri A, Tibor A, Mertens P, DeBolle X, Michel P, Godfroid J,Walravens K, Letesson JJ (2001) Induction of immune response in $\mathrm{BALB} / \mathrm{c}$ mice with a DNA vaccine encoding bacterioferritin or P39 of Brucella spp. Infect Immun 69: 6264-6270.

18. Roop RM, Fletcher TW, Sriranganathan NM, Boyle SM, Schurig GG (1994) Identification of an immunoreactive Brucella abortus HtrA stress response protein homolog. Infect Immun 62: 1000-1007.

19. Baloglu S, Toth TE, Schurig GG, Sriranganathan N, Boyle SM (2000) Humoral immune response of BALB/c mice to a vaccinia virus recombinant expressing Brucella abortus GroEL does not correlate with protection against a $B$. abortus challenge. Vet Microbiol 76: 193-199.

20. Lin J, Adams LG, Ficht TA (1996) Immunological response to the Brucella abortus GroEL homolog. Infect Immun 64: 4396-4400.

21. Leclerq S, Harms JS, Rosinha GM, Azevedo V, Oliveira SC (2002) Induction of a Th1-type of immune response but not protective immunity by intramuscular DNA immunisation with Brucella abortus GroEL heat-shock gene. J Med Microbiol 51: 20-26.

22. Singha H, Mallick AI, Jana C, Isore DP, Goswami TK, Srivastava SK, Azevedo VA, Chaudhuri P, Owais M (2008) Escheriosomes entrapped DNA vaccine co-expressing $\mathrm{Cu}-\mathrm{Zn}$ superoxide dismutase and IL-18 confers protection against Brucella abortus. Microbes Infect 10: 1089-1096.

23. Tabatabai LB and Pugh GW (1994) Modulation of immune responses in BALB/c mice vaccinated with Brucella abortus $\mathrm{Cu}-\mathrm{Zn}$ superoxide dismutase synthetic peptide vaccine. Vaccine 12: 919-924. 
24. Vemulapalli R, Cravero S, Calvert CL, Toth TE, Sriranganathan N, Boyle SM, Rossetti OL, Schurig GG (2000) Characterization of specific immune responses of mice inoculated with recombinant vaccinia virus expressing an 18kilodalton outer membrane protein of Brucella abortus. Clin Diagn Lab Immunol 7: 114-118.

25. Oliveira SC and Splitter GA (1996) Immunization of mice with recombinant $\mathrm{L} 7 / \mathrm{L} 12$ ribosomal protein confers protection against Brucella abortus infection. Vaccine 14: 959-962.

26. Cassataro J, Velikovsky CA, de la Barrera S, Estein SM, Bruno L, Bowden R, Pasquevich KA, Fossati CA, Giambartolomei GH (2005) A DNA vaccine coding for the Brucella outer membrane protein 31 confers protection against $B$. melitensis and $B$. ovis infection by eliciting a specific cytotoxic response. Infect Immun 73: 6537-6546.

27. Zhao Z, Li M, Luo D, Xing L, Wu S, Duan Y, Yang P, Wang $X$ (2009) Protection of mice from Brucella infection by immunization with attenuated Salmonella enterica serovar typhimurium expressing A L7/L12 and BLS fusion antigen of Brucella. Vaccine 27: 5214-5219.

28. Cassataro J, Pasquevich KA, Estein SM, Laplagne DA, Zwerdling A, de la Barrera S, Bowden R, Fossati CA, Giambartolomei GH, Goldbaum FA (2007) A DNA vaccine coding for the chimera BLSOmp31 induced a better degree of protection against $B$. ovis and a similar degree of protection against $B$. melitensis than Rev.1 vaccination. Vaccine 25: 5958-5967.

29. Velikovsky CA, Cassataro J, Giambartolomei GH, Goldbaum FA, Estein S, Bodwen RA, Bruno L, Fossati CA, Spitz M (2002) A DNA vaccine encoding lumazine synthase from Brucella abortus induce protective immunity in BALB/c mice. Infect Immun 70: 2507-2511.

30. Castañeda-Roldán EI, Ouahrani-Bettache S, Saldaña Z, Avelino-Flores F, Rendón MA, Dornand J, Girón JA (2006) Characterization of SP41, a surface protein of Brucella associated with adherence and invasion of host epithelial cells. Cell Microbio 8: 1877-1887.

31. Castañeda-Roldán EI, Avelino-Flores F, Dall'Agnol M, Freer E, Cedillo L, Dornand J, Girón JA (2004) Adherence of Brucella to human epithelial cells and macrophages is mediated by sialic acid residues. Cell Microbiol 6: 435-445.

32. Al-Mariri A (2010) Protection of BALB/c mice against Brucella melitensis $16 \mathrm{M}$ infection induced by vaccination with live Escherchia coli expression Brucella P39 protein. Vaccine 28: 1766-1770.

33. Gurunathan S., Klinman DM, Seder RA (2000) DNA vaccines: immunology, application, and optimization. Annu Rev Immunol 18: 927-974.

34. Kalinna BH (1997) DNA vaccines for parasitic infections. Immunol Cell Biol 75: 370-375.

35. Donnelly JJ, Ulmer JB, Shiver JW, Liu MA. DNA vaccines (1997) Annu Rev Immunol 15: 617-648.

36. On ate AA, Cespedes S, Cabrera A, Rivers R, Gonzalez A, Munoz C,Folch H, Andrews E (2003) A DNA vaccine encoding $\mathrm{Cu}-\mathrm{Zn}$ superoxide dismutase of Brucella abortus induces protective immunity in BALB/c mice. Infect Immun 71: 4857-4861.

37. Cutler SJ, Whatmore AM, Commander NJ (2005) Brucellosis--new aspects of an old disease. J Appl Microbiol 98: 1270-1281.

38. Kurar E and Splitter GA (1997) Nucleic acid vaccination of Brucella abortus ribosomal L7/L12 gene elicits immune response. Vaccine 15: 1851-1857.

39. Luo D, Ni B, Li P, Shi W, Zhang S, Han Y, Mao L, He Y, Wu Y, Wang X (2006) Protective immunity elicited by a divalent DNA vaccine encoding both the L7/L12 and Omp16 genes of Brucella abortus in BALB/c mice. Infect Immun 74: 2734-2741.

40. Yu DH, Hu XD, Cai H (2007) A combined DNA vaccine encoding BCSP31, SOD, and L7/L12 confers high protection against Brucella abortus 2308 by inducing specific CTL responses. DNA Cell Biol 26: 435-443.

\section{Corresponding author}

Ayman Al-Mariri

Department of Molecular Biology and Biotechnology

Atomic Energy Commission

PO Box 6091

Damascus, Syria

Telephone/Fax: 963-11-213580/963-11-6112289

Email: ascientific1@aec.org.sy

Conflict of interests: No conflict of interests is declared. 